\title{
Los servicios públicos locales: reforma de la Administración local en tiempos de crisis económica
}

\author{
JuAN ANTONIO ChINCHILLA ${ }^{1}$ \\ MÓNICA DOMÍNGUEZ ${ }^{2}$
}

\section{RESUMEN}

Este trabajo se centra en el intento de la Ley 27/2013, de Racionalización y Sostenibilidad de la Administración Local, de limitar, al socaire del principio de equilibrio presupuestario, los servicios públicos que hasta el momento venían prestando las entidades locales. El punto de partida es el análisis de las medidas adoptadas como consecuencia de la crisis económica, así como de las medidas normativas de reforma de la Administración local. De este marco se derivan un nuevo régimen de las competencias locales, la reforma de los modos de gestión de los servicios públicos, así como novedades relativas al papel y la intervención local en la iniciativa económica y en la reserva de recursos y servicios esenciales al ámbito local.

Palabras clave: Administración local, servicios públicos locales, externalización, reforma de la Administración.

1 Doctor en Derecho y catedrático de la Universidad Autónoma de Madrid, Madrid, España. Correo-e: juanantonio.chinchilla@uam.es

2 Doctora en Derecho y catedrática de la Universidad Autónoma de Madrid, Madrid, España. Correo-e: monica.dominguez@uam.es Fecha de recepción: 11 de agosto de 2015. Fecha de modificación: 11 de septiembre de 2015. Fecha de aceptación: 15 de octubre de 2015. Para citar el artículo: ChinCHILlA, J. y DominguéZ, M. (2015). Los servicios públicos locales: reforma de la Administración local en tiempos de crisis económica. Revista Digital de Derecho Administrativo n. ${ }^{\circ}$ 14, Universidad Externado de Colombia, pp. 45-63. DOI: http:// dx.doi.org/10.18601/21452946.n14.05 


\section{Local public services: local government reform in a time of economic crisis}

\section{ABSTRACT}

This work focuses on the intent of Law 27/2013, which addresses the streamlining and sustainability of the local government in order to limit local public services under the principle of budgetary equilibrium. The starting point of this paper is the analysis of the measures taken as a result of the economic crisis and policy measures to reform the local government. This framework formulates a new system of local competences, a reform to the methods in which public services are managed, as well as developments concerning the local role and involvement of economic initiatives and the reservation of resources and essential services at the local level.

Keywords: Local Government, local public services, outsourcing, institutional reform.

\section{LA REORGANIZACIÓN DE LA ADMINISTRACIÓN LOCAL EN EL CONTEXTO DE LA CRISIS ECONÓMICA}

1. La organización, o mejor, la reorganización de todo el sector público español y, en lo que aquí interesa, de la Administración municipal, constituye un tema central en el debate político y jurídico actual. La reforma y la racionalización de las estructuras administrativas ocupan una posición central en el debate social y político, así como en la discusión sobre las medidas a adoptar para recortar el gasto público y superar la grave crisis económica y financiera que hemos venido padeciendo, de la que parece vislumbrarse un incierto final. Las reformas administrativas se han situado en los primeros puestos de la agenda política a medida que se ha advertido la importancia de la maquinara pública para la realización de las líneas de actuación gubernamentales y su enorme incidencia en el gasto público. Y estas políticas de reforma administrativa se han extendido en todos los países, convirtiéndose en un elemento común de la acción gubernamental (Cassese, 2006, pp. 193-194)33.

La vigencia de estas afirmaciones se pone de manifiesto cada día en los medios de comunicación y en las intervenciones públicas de nuestros gober-

3 Sobre las transformaciones que está experimentando el sector público por la crisis económica ver los interesantes trabajos de MOnTOYA Martín (2011); MONTOYA Martín (2012); Montoya MarTín (2014); Cosculluela y MEdina (2012); EMbid Irujo (2012); FonT y Galán (2012); Ortega Jiménez (2012); Carbonell Porras (2013); Santiago Iglesias (2013); Domínguez Martín y Rodríguez-Chaves Mimbrero (2013). 
nantes. Así, por citar algunas de las iniciativas gubernamentales al respecto ${ }^{4}$, el Consejo de Ministros de 27 de abril de 2012 aprobó la Actualización del Programa de Estabilidad 2012-2015 y el Programa Nacional de Reformas 2012, que incluye la adopción de medidas de modernización de las Administraciones Públicas y de los servicios públicos, consistentes en la racionalización de su tamaño, estructura y tareas; en el Consejo de Ministros de 5 de octubre de 2012 se presentó el Informe del Ministro de Hacienda y Administraciones Públicas sobre la situación del sector público empresarial en España, en el que se fijan los objetivos a seguir en relación con su sector empresarial, tanto por la Administración estatal como por la autonómica y local: su reducción, el control de su actividad y la racionalización de su organización; y el 26 de octubre de 2012, el Gobierno anunció la creación de una Comisión para auditar todas las Administraciones Públicas, incluida, claro está, la Administración local, comprometiéndose a elaborar antes del 30 de junio de 2013 una propuesta de reforma integral de las Administraciones públicas, de manera que se simplifique y adelgace su estructura y se evite cualquier tipo de duplicidad entre ellas. Esta Comisión se estructura en cuatro subcomisiones, relativas, respectivamente, a duplicidades, simplificación administrativa, gestión de servicios y medios comunes y administración institucional ${ }^{5}$.

2. La racionalización y la evolución del sector local hacia un modelo más eficaz y eficiente para el desempeño de las competencias que el ordenamien-

4 Todo ello en el contexto normativo marcado por el Pacto de Estabilidad y Crecimiento de la Unión Europea, adoptado en el Consejo de Ámsterdam, de junio de 1997, en el que se limitó la utilización del déficit público como instrumento de política económica. En el plano nacional, la reformulación de la política presupuestaria se ha ido paulatinamente abordando a través de varios instrumentos normativos: Ley 18/2001, de 12 de diciembre, General de Estabilidad Presupuestaria; Ley Orgánica 5/2001, de 13 de diciembre, complementaria de la Ley General de Estabilidad Presupuestaria; Ley 15/2006, de 26 de mayo, de reforma de la Ley 18/2001, Real Decreto 1463/2007, de 2 de noviembre, por el que se aprueba el reglamento de desarrollo de la Ley 18/2001, de 12 de diciembre, de Estabilidad Presupuestaria, Real Decreto Legislativo 2/2007, de 28 de diciembre, por el que se aprueba el Texto Refundido de la Ley de Estabilidad Presupuestaria. El proceso culmina con la modificación, en el año 2011, del artículo 135 CE, con el fin de limitar el déficit público de carácter estructural y la deuda pública y que luego fue desarrollado por la Ley Orgánica 2/2012, de 27 de abril, de Estabilidad Presupuestaria. Ya en el ámbito puramente local, se elabora la Ley 27/2013, de Racionalización y Sostenibilidad de la Administración Local.

5 En declaraciones de 26 de octubre de 2012, de la Vicepresidenta del Gobierno, Soraya Sáenz de Santamaría, "Vamos a analizar y proponer cambios de estructuras, competencias y procedimientos, vamos a organizarnos mejor para ser mejores. [...] Hay una gran pluralidad de organismos públicos y tendremos que saber qué es lo que hay, si pueden eliminarse algunos, fusionarse, si son necesarios o no [...] No podemos seguir aumentando estructuras. Queremos una Administración simple, eficiente y mucho más coordinada". En: http://www.elderecho.com/actualidad/Gobierno-estudiar-integral-administracionespublicas_0_466125191.html 
to jurídico otorga a las entidades locales pasa por el estudio y diseño de un mapa municipal acorde a las necesidades demográficas, económicas y sociales actuales y orientado a formas más lógicas de prestación de servicios a los ciudadanos, eliminando y evitando en lo posible duplicidad de actuaciones y solapamiento de competencias no solo entre distintas entidades locales, sino entre distintas Administraciones Públicas. Simultáneamente, se hace necesario abordar integralmente la reforma de las funciones y servicios públicos cuya prestación se encomienda a la Administración local mediante la atribución de un elenco cerrado de competencias precisas que permitan garantizar su suficiencia financiera. Asimismo, se extiende la idea de la necesidad de evitar la actual proliferación de entidades instrumentales mediante su vinculación con la ejecución de los servicios públicos prestacionales o con el desarrollo de actividades económicas, con expresa exclusión de aquellos servicios meramente administrativos (Montoya Martín, 2011, p. 78) ${ }^{6}$.

3. En un contexto de crisis económica tan intenso como el que vivimos, a la Administración ya no solo se le exige que lleve a cabo las funciones que tiene encomendadas, sino que, además, lo tiene que hacer de manera que sea lo más eficaz posible, con los mejores resultados a los que se pueda llegar y con el menor coste. En la Exposición de Motivos del Anteproyecto de la tan publicitada y esperada Ley de Transparencia, Acceso a la Información Pública y Buen Gobierno $^{7}$ se afirma que "las Administraciones y entidades públicas de todo tipo deben contar con los factores organizativos que les permitan satisfacer el derecho de los ciudadanos a una buena administración, que se va consolidando en el espacio europeo, y contribuir al desarrollo económico y social". En la versión finalmente aprobada de la Ley 9/2013, de 9 de diciembre, cambia la redacción de la Exposición de Motivos, incluyendo la siguiente referencia, en lo que aquí interesa: "En materia de información institucional, organizativa y de planificación exige a los sujetos comprendidos en su ámbito de aplicación la publicación de información relativa a las funciones que desarrollan, la normativa que les resulta de aplicación y su estructura organizativa, además de sus instrumentos de planificación y la evaluación de su grado de cumplimiento".

4. Por tanto, puede concluirse que la reorganización de la entidad local, así como de su sector público instrumental, constituye uno de los contenidos fundamentales de los Planes de ajuste (Montoya Martín, 2011, p. 191). Esta misma idea está presente en las Resoluciones y Comunicaciones de la Federa-

6 MONTOYA MarTín (2012, p. 173), además, señala que es necesario el establecimiento de registros válidos y permanentemente actualizados que permitan delimitar el sector público local.

7 Anteproyecto de Ley aprobado por Acuerdo de Consejo de Ministros de 23 de marzo de 2012 y Proyecto de Ley de 27 de julio de 2012. 
ción Española de Municipios y Provincias (X Asamblea General, noviembre de 2011), que apuestan por una reordenación y modernización de la Administración local, con medidas de transparencia para dar cuenta a los ciudadanos de forma continuada del estado financiero de sus corporaciones locales y, al tiempo, racionalizar el entramado de organismos y empresas públicas.

\section{EL LÍMITE PRESUPUESTARIO IMPUESTO POR LA LEGISLACIÓN ESTATAL}

5. Del análisis de las medidas adoptadas como consecuencia de la crisis económica, así como de las medidas normativas de reforma de la Administración local, se derivan un nuevo régimen de las competencias locales, la reforma de los modos de gestión de los servicios públicos, así como novedades relativas al papel y la intervención local en la iniciativa económica y en la reserva de recursos y servicios esenciales al ámbito local. Aquí se va a poner el foco de atención en dos aspectos: la intervención local en la iniciativa económica y la determinación del modo de gestión de los servicios públicos locales.

6. En lo que hace a la reforma de los modos de gestión de los servicios públicos, el informe Cora parecía apuntar en la buena dirección cuando "aprecia la necesidad de reformar el actual marco normativo regulador de los entes del sector público, sustituyendo las diversas clasificaciones de entes públicos por una sola, que contenga una precisa delimitación y una visión integrada de los diferentes tipos actualmente existentes" (p. 217). No se trata solo de unificar la terminología, aprobando "un marco normativo común, mínimo pero básico, que ordene la dispersión y heterogeneidad que existen en la actualidad", sino de que "la tipología de organismos públicos existentes sea clara y precisa", lo que implica una identificación de cada tipo de organismo y de las funciones que debe cumplir. Se trata, sin duda, de una de las cuestiones más trascendentes para el proceso de reforma administrativa, pues no se trata solo de suprimir organismos inútiles, sino de conocer para qué sirven los existentes y cuál es la opción organizativa más adecuada en cada caso. La cuestión entonces es clara: ¿qué reflejo ha tenido esto en la reforma de la Administración local?

7. La Ley 27/2013, de 27 de diciembre, de Racionalización y Sostenibilidad de la Administración Local, proclama, en su Exposición de Motivos, que sus objetivos son: la clarificación de las competencias municipales; la racionalización de la estructura organizativa de la Administración local de acuerdo con los principios de eficiencia, estabilidad y sostenibilidad financia, un control financiero y presupuestario más riguroso, y favorecer la iniciativa privada (supresión de monopolios municipales del art. 84 bis LBRL y reforma de la iniciativa pública económica local del art. 86.1 LBRL). 
El Anteproyecto de Ley incorporaba una modificación del artículo 86 LBRL. Esta propuesta apostaba por la subsidiariedad económica, exigía la incorporación al expediente acreditativo de la conveniencia y oportunidad de la iniciativa económica local y la justificación de que se prestan todos los servicios mínimos obligatorios con arreglo a los estándares de calidad establecidos, así como que la iniciativa no generaba riesgo para la sostenibilidad financiera del municipio, ni en lo relativo al mantenimiento de los referidos servicios, ni a la propia actividad fruto de la iniciativa pública. Más allá del deber de motivación, se imponía una exigencia de acreditación de viabilidad económica. Aunque, en realidad, estas previsiones solo refuerzan otras que ya se encuentran en nuestro ordenamiento jurídico: en la Ley de Estabilidad Presupuestaria, en la Ley de Economía Sostenible (que requiere un análisis de sostenibilidad en el medio plazo de cualquier iniciativa administrativa) y en la propia Ley de Bases del Régimen Local (cuyas exigencias procedimentales podrían interpretarse en este sentido). Con todo, es cierto que en muchos casos tales exigencias no han sido escrupulosamente respetadas, incidiendo negativamente en el presupuesto y en los servicios básicos e imprescindibles. Por lo tanto, insistir en estas cautelas no está de más. Pero es que, de otra parte, la propuesta del Anteproyecto iba más allá, al imponer asimismo la realización de "un análisis de mercado relativo a la oferta existente, y a los posibles efectos de la actividad local sobre la concurrencia empresarial". El comentario que acompaña a la propuesta de modificación del artículo 86 evidencia, además, el propósito de la reforma, invocando el carácter subsidiario de la iniciativa económica local, a la que de otro lado se subordina a la aprobación definitiva por parte del órgano de gobierno de la Comunidad Autónoma, aprobación que antes se contemplaba exclusivamente para el caso de los servicios prestados en monopolio, con exclusión pues de la iniciativa privada.

Finalmente, estas exigencias contenidas en el Anteproyecto de Ley se han reducido al desaparecer algunas de ellas en la versión final de la Ley para la Racionalización y Sostenibilidad de la Administración Local, en la que el artículo 86 se centra en la exigencia de que la iniciativa pública para el desarrollo de actividades económicas no genere riesgo para la sostenibilidad financiera del conjunto de la Hacienda municipal, debiendo contener un análisis del mercado, relativo a la oferta y a la demanda existente, a la rentabilidad y a los posibles efectos de la actividad local sobre la concurrencia empresarial. Corresponde al pleno de la respectiva corporación local la aprobación del expediente, que determinará la forma concreta de gestión del servicio. En relación con esto y la elección de la forma concreta de gestión, el artículo 85.2, párrafo, establece que solo podrá gestionarse a través de entidades públicas empresariales o sociedades mercantiles de capital íntegramente público cuando se acredite que son formas más eficientes que la gestión por la propia entidad o a través de organismo autónomo local. Por último, en el apartado 2 del artículo 86 se 
limita la exigencia de aprobación por el órgano competente de la Comunidad Autónoma solo a los supuestos de "actividades en régimen de monopolio".

8. En definitiva, la reforma en este ámbito no ha sido de tanta trascendencia y calado como parecía intuirse en los años anteriores, si bien se aumentan, de manera tibia, los controles y los requisitos de configuración de la Administración instrumental local y se limita la potestad de autoorganización local (Montoya Martín, 2014)

Finalmente, el elemento clave de la reforma lo constituye la redefinición y reclasificación de las competencias municipales, lo que implica, finalmente, una reducción de la actividad municipal, a la que se le imputa constituir una fuente del déficit financiero, y su trasvase a la libre iniciativa de los particulares. Con esta finalidad, la ley incluye un nuevo tipo de competencias municipales (las "distintas de las propias", según el art. 7.4 LBRL); reduce el listado de materias de necesaria competencia municipal (art. 25.2 LBRL), y suprime la competencia universal "complementaria" del artículo 28 LBRL. En la determinación de lo que constituyen competencias "propias" e "impropias" de las entidades locales, la garantía de suficiencia presupuestaria se configura como el único límite a los servicios públicos. Conforme a esto, los servicios que obligatoriamente tienen que prestar los municipios son "competencias propias". Pueden prestar otros pero, para poder hacerlo, requieren acreditar la suficiencia presupuestaria para asumir el coste efectivo de esos servicios, o que reciben financiación de la Comunidad Autónoma correspondiente (Velasco Caballero, 2014a; 2014b; 2014c; Montoya Martín, 2014).

\section{EL LÍMITE NORMATIVO AUTONÓMICO. EL VACIAMIENTO DE LOS REQUISITOS DE LA LRSAL POR LA NORMATIVA AUTONÓMICA}

9. Al margen de la propia aplicación preferente de la regulación especial de los municipios de Barcelona y Madrid, salvo cuando entren en colisión con los principios de estabilidad presupuestaria y sostenibilidad financiera, Disposición Adicional 5ª . LRSAL (Galán Galán, 2015, p. 8), diversas normas autonómicas garantizan la competencia municipal sobre servicios públicos atribuidos previamente por leyes autonómicas, obstaculizando la aplicación de la LRSAL (Velasco Caballero, 2015; Galán Galán, 2015, P. 14; Navarro Rodríguez y Zafra Víctor, 2014, p. 10), y ello con independencia del color político del

8 Que afirma que tanto el texto como la reforma adolecen de claras insuficiencias que mal se acomodan al título de la ley que se anuncia como "racionalizadora", pues actúa sobre un traje de hace casi treinta años abundando en sus insuficiencias y defectos $y$, por otra parte, es sesgada, toda vez que prima el criterio económico. 
gobierno autonómico. En efecto, para que las entidades locales puedan ejercer competencias distintas de las propias y de las atribuidas por delegación, el artículo 7.4 LBRL exige un informe previo de la Administración competente por razón de la materia en el que se señale la inexistencia de duplicidades. En unos casos, la legislación autonómica considera que ello solo ocurrirá respecto de nuevas competencias, no siendo de aplicación a las competencias que los entes locales vengan ya ejerciendo. Operará, pues, únicamente de cara al futuro. Aquí la normativa autonómica configura de manera indirecta los servicios que efectivamente vienen prestando los municipios como competencias propias municipales ${ }^{9}$. En otros casos, en cambio, se considera que corresponde a los propios entes locales determinar si los servicios que vienen prestando incurren en duplicidad, de manera que si el juicio es negativo no será preciso solicitar autorización alguna a ninguna otra Administración ${ }^{10}$.

10. Estas normas autonómicas, las cuales pretenden blindar las competencias y servicios prestados por los Ayuntamientos a través de la interpretación y precisión de la regulación de la LRSAL plantean problemas acerca de su adecuación constitucional. Las posibles antinomias expresan un conflicto competencial que, en su caso, será resuelto por el Tribunal Constitucional. Pero hasta tal momento, las entidades locales deben decidir qué norma aplican. Si no resulta posible una reducción lógica de la antinomia mediante una interpretación adecuada de las normas estatal y autonómicas, el Ayuntamiento deberá proceder a aplicar aquella norma que considere procedente a partir de los criterios materiales proporcionados por la Constitución (Velasco Caballero, 2014a, p. 17) ${ }^{11}$. En el caso de los servicios públicos, la base material será el artículo 9.2 de la Constitución y los distintos derechos sociales. Ahora bien, lo cierto es que hasta el momento los ayuntamientos no han reducido

9 Por ejemplo, la Ley madrileña 1/2014, de 25 de julio, de Adaptación del Régimen Local de la Comunidad de Madrid a la Ley 27/2013, de 27 de diciembre, de Racionalización y Sostenibilidad de la Administración Local, determina que "Las competencias atribuidas a los Municipios por leyes anteriores a la entrada en vigor de la Ley 27/2013, de 27 de diciembre, de Racionalización y Sostenibilidad de la Administración Local, se ejercerán por los mismos de conformidad con las previsiones contenidas en la norma de atribución, en régimen de autonomía y bajo su propia responsabilidad, de acuerdo con el artículo 7.2 de la Ley 7/1985, de 2 de abril, Reguladora de las Bases del Régimen Local, sin perjuicio de lo dispuesto en la presente Ley". En la misma línea, la Ley 5/2014, de 27 de mayo, de medidas urgentes derivadas de la entrada en vigor de la Ley 27/2013, de 27 de diciembre, de racionalización y sostenibilidad de la Administración local de Galicia.

10 Por ejemplo, los artículos. 2.3 y 4 del Decreto-ley andaluz 7/2014, de 20 de mayo, por el que se establecen medidas urgentes para la aplicación de la LRSAL; o el artículo 4.1 del Decreto asturiano 68/2014, de 10 de julio, por el que se regula el procedimiento para la obtención de los informes previstos en el artículo 7.4 de la LBRL.

11 Es más, las entidades locales podrán adoptar instrucciones organizativas sobre la aplicación de la LRSAL. 
claramente sus ámbitos de actividad. Cuestión distinta es que, dentro de sus ámbitos materiales, el gasto municipal sí ha sido notoriamente inferior, pero no como consecuencia de la reducción de los servicios públicos municipales, sino de la aplicación de los distintos instrumentos de estabilidad presupuestaria y sostenibilidad financiera.

\author{
IV. EL LÍMITE FORMAL: PROCEDIMIENTO \\ DE EXTERNALIZACIÓN E INFORMACIÓN PÚBLICA. \\ ¿SE GARANTIZAN SUFICIENTEMENTE LOS INTERESES \\ DE LOS CIUDADANOS/USUARIOS DE LOS SERVICIOS \\ PÚBLICOS? EL EJEMPLO DEL SERVICIO DE \\ ABASTECIMIENTO DE AGUA POTABLE
}

\begin{abstract}
A) LA RESERVA LEGAL DEL SERVICIO PÚBLICO DE ABASTECIMIENTO DE AGUA DEL ARTíCULO 86.3 DE LA LEY DE BASES DE RÉGIMEN LOCAL PERMITE TANTO UNA GESTIÓN DIRECTA COMO UNA GESTIÓN INDIRECTA DEL SERVICIO. SU CONEXIÓN CON LA FIGURA DE LA "MUNICIPALIZACIÓN" DEL REGLAMENTO DE SERVicios de las Corporaciones LoCALES DE 1955
\end{abstract}

11. De conformidad con el artículo 25.2.c) de la Ley 7/1985, de 2 de abril, Reguladora de las Bases del Régimen Local, y en el marco de su competencia para promover toda clase de actividades y prestar cuantos servicios públicos contribuyan a satisfacer las necesidades de los vecinos, los Municipios ejercerán competencias, en los términos de la legislación del Estado y de la Comunidad Autónoma, en materia de suministro de agua, imponiéndoseles la obligación de prestación mínima de dicho servicio en el artículo 26.1.a) para todos los Municipios sin distinción en función de su población. Esta materia puede ser considerada ya sea como una actividad económica o como un servicio público de contenido económico (Gallego Anabitarte, 2003, pp. 13-14).

12. A su vez, y como es sabido, el artículo 86.2 de la Ley $7 / 1985$, declara la reserva a favor de la Entidad Local, en cuanto servicio esencial, del abastecimiento y depuración de aguas. Se precisa que si la efectiva ejecución de tal actividad se presta en régimen de monopolio se requerirá, además de la aprobación por el Pleno del Ayuntamiento, la aprobación por el órgano de la Comunidad Autónoma. Esto es, se trata de una actividad económica que debe ser ejercida exclusivamente por el Ayuntamiento por la propia naturaleza de las cosas dado su carácter de servicio esencial para el desarrollo de la vida de la comunidad municipal. La expresión reserva adoptada por el artículo 86.2 
debe ser entendida (Gallego Anabitarte, 2003, p. 18) ${ }^{12}$ como una "negación radical de la libertad de empresa" en esa materia, atribuyendo en exclusiva dicha actividad económica/servicio público de contenido económico al municipio. Desde este planteamiento, solo el Ayuntamiento puede, prima facie, ejercer dicha actividad de abastecimiento de agua, mediante su gestión directa o indirecta.

13. En efecto, la prestación de tal servicio público reservado de abastecimiento y depuración de aguas puede ser efectuada por el municipio, de conformidad con el artículo 95 del Real Decreto Legislativo 781/1986, de 18 de abril, por el que se aprueba el Texto Refundido de las Disposiciones legales vigentes en materia de Régimen Local, tanto a través de un sistema de gestión directa como a través de un sistema de gestión indirecta. Esto es, el servicio público reservado (en cuanto excluye la libertad de empresa) puede ser prestado en régimen de monopolio, en cuyo caso solo podrá existir un gestor (directo o indirecto del servicio), o no, en cuyo caso cabe la posibilidad de la existencia de varios concesionarios si se gestiona indirectamente (Gallego Anabitarte, 2003, p. 19; Molina Jiménez, 2001, p. 188). En todo caso la municipalización de servicios, sea o no en régimen de monopolio, tiene como límite objetivo el término municipal, sin que pueda suponer autorización para rebasar el ámbito espacial de la prestación del servicio, puesto que la competencia municipal se circunscribe al territorio de su jurisdicción ${ }^{13}$.

14. El artículo 22.2.f) de la Ley de Bases atribuye al Pleno la competencia para "la aprobación de las formas de gestión de los servicios y de los expedientes de municipalización", exigiéndose en el artículo 47.2.k) del mismo cuerpo legal el voto favorable de la mayoría absoluta del número legal de miembros de la corporación local para adoptar el acuerdo de "municipalización [...] en régimen de monopolio y aprobación de la forma concreta de gestión del servicio correspondiente...".

15. El artículo 86.2 de la Ley de Bases exige la tramitación de un procedimiento para prestar un servicio reservado en régimen de monopolio donde se determine la forma concreta de gestión del servicio, y su posterior aprobación por el órgano autonómico. Esta previsión se desarrolla en el artículo 97 del Texto Refundido, donde se requiere que en el expediente se acredite la conveniencia

12 Por el contrario, Díaz Lema (1994, p. 81) consideró que el artículo 86.3 únicamente incorpora una previsión legal de que determinadas actividades puedan ejercerse por el Ayuntamiento en régimen de monopolio pero que, mientras no se adopte dicha decisión, las mismas se ejercerán en régimen de libre concurrencia por los particulares.

13 En consecuencia, si la municipalización afecta a varios términos municipales se precisa la adopción de los correspondientes acuerdos por los Ayuntamientos respectivos, como precisa la Sentencia del Tribunal Supremo de 9 de diciembre de 2002 (Recurso de Casación n. $\left.{ }^{\circ} 3882 / 1997\right)$. 
de la prestación del servicio en régimen de monopolio. El elemento formal donde se acredita dicha conveniencia es la Memoria, en la que debe precisarse además la forma de gestión que se adopta.

Aquí, los intereses que concurren y que exigen como técnica de tutela la necesidad de acreditar, a través del previo expediente, la conveniencia y oportunidad de la medida encaminada al ejercicio de la iniciativa pública en el ejercicio de actividades económicas, que excluyan la libre iniciativa privada en la prestación de un servicio reservado, son evidentes. De una parte, el interés de los vecinos en recibir la prestación adecuada de un servicio esencial, respecto del que tienen un derecho a exigir tal prestación, artículo 26.1 de la Ley de Bases. De otra parte, aquellos sujetos que pueden prestar en régimen de libre concurrencia una actividad económica que ahora se ve excluida dada su reserva al sector público. El expediente previo para declarar la prestación del servicio en régimen de monopolio, que debe someterse a información pública, persigue acreditar la oportunidad y conveniencia de la medida. Este requisito aparece justificado por el carácter excepcional que, desde el punto de vista de los principios de libre empresa y libertad de mercado (art. 38 de la Constitución) reviste la intervención pública en la actividad económica (art. 128 de la Constitución). La existencia de esa intervención pública no resulta afectada por el hecho de que la actividad económica de que se trate se haya reservado al poder público como servicio esencial en régimen de monopolio (art. 128.2, inc. segundo, de la Constitución). La naturaleza y la finalidad de dicho expediente lo convierten en presupuesto procedimental esencial para legitimar la intervención del poder público en la actividad económica privada, tal como aparece configurado en la ley de acuerdo con los principios constitucionales ${ }^{14}$. Aquí debe encontrarse la justificación del sometimiento a información pública de la Memoria.

B) LA DECISIÓN DE ADOPTAR UNA FORMA DE GESTIÓN INDIRECTA, QUE SUSTITUYA A UNA GESTIÓN DIRECTA, NO AFECTA A LA DECISIÓN DE PRESTAR EL SERVICIO EN RÉGIMEN DE MONOPOLIO, POR LO QUE NO RESULTA NECESARIO TRAMITAR UN PROCEDIMIENTO PARA DECLARAR LA MONOPOLIZACIÓN

16. Evidentemente, la encomienda por una autoridad pública a un tercero de la prestación de actividades de servicios públicos (externalización de la gestión del servicio público) no supone un cuestionamiento del carácter público del servicio. No hay una nueva municipalización o una modificación de la reserva al sector público, lo que tiene una directa influencia en el procedimiento a seguir para llevar a cabo tal externalización. La posibilidad de

14 Como precisó la Sentencia del Tribunal Supremo de 1 de febrero de 2002 (Recurso de Casación n. ${ }^{\circ}$ 6139/1996). 
que los servicios reservados, de una parte, se presten por el Ayuntamiento en régimen de monopolio o no, lo que permite la existencia de un único gestor o de varios, y de otra parte, que deba optarse por una gestión directa o indirecta, obliga a distinguir en esta materia dos ámbitos de decisión que deben ser adoptados por la Administración municipal, en su caso a través de un único procedimiento administrativo o a través de sendos y sucesivos procedimientos administrativos. De una parte, el régimen de prestación del servicio, donde el municipio debe optar por la figura del monopolio, que implica un único gestor, o la posibilidad de varios gestores. De otra parte, la forma de gestión del servicio monopolizado, a través de cualquiera de los modos de gestión de los servicios locales regulados en el artículo 85.2.A) -gestión directa- o en el artículo 85.2.B) -gestión indirecta- de la Ley de Bases de Régimen Local.

17. Con carácter general, la decisión municipal que se pronuncia por vez primera sobre un determinado servicio debe determinar tanto el régimen de prestación como la forma de gestión del servicio, a tenor de los artículos 86.2 de la Ley de Bases (por remisión al apartado 2: forma concreta de gestión) y 97 del Texto Refundido (acuerdo que decide el régimen de monopolio y determinación de la forma de gestión). Esto es, en ese caso el procedimiento es único, debiendo contener ambos pronunciamientos en una única resolución. De una parte, la decisión sobre la forma de prestación que, si es el monopolio, requiere la posterior aprobación del órgano de gobierno autonómico. Y, de otra parte, la decisión sobre la forma de gestión que, si es la concesión, requerirá la posterior tramitación del expediente de contratación. No cabe que la convocatoria y adjudicación de tal expediente de contratación se realice con anterioridad a la determinación de la forma de prestación del servicio y de la forma de gestión del mismo. Pero si ya hay una previa decisión de la Administración sobre el régimen de prestación del servicio, mientras esta no se altere, si el municipio decide variar únicamente la forma de gestión concreta, este será el único punto sobre el que habrá de pronunciarse, no siendo necesario tramitar nuevamente un expediente de municipalización sometido a la posterior aprobación del órgano competente de la Comunidad Autónoma ${ }^{15}$. Se limita así el control autonómico al momento inicial de proceder a la prestación del servicio en régimen de monopolio, como exigencia derivada del respeto al principio constitucional de autonomía local, quedando excluidos de tal control autonómico las posteriores actuaciones que incidan sobre la prestación del servicio. En todo caso, la prestación en régimen de monopolio solo puede acordarse si previamente el servicio o actividad se realiza por los particulares, puesto que si este efectivamente viene prestándose por el Ayun-

15 Cfr. la Sentencia del Tribunal Supremo de 21 de diciembre de 2000 (Recurso de Casación n. $\left.{ }^{\circ} 6448 / 1996\right)$. 
tamiento en cuanto servicio reservado no será procedente la incoación del procedimiento al efecto.

La interpretación aquí mantenida se confirma igualmente por el derecho positivo autonómico dictado en desarrollo y complemento de la Legislación Básica del Estado. Así, por ejemplo, el Decreto 347/2002, de 19 de noviembre, por el que se aprueba el Reglamento de Bienes, Actividades, Servicios y Obras de las Entidades Locales de la Comunidad de Aragón, afirma que las Entidades Locales podrán ejercer actividades económicas en régimen de libre concurrencia, salvo que se trate de una actividad reservada, en cuyo caso deberá necesariamente prestarse en régimen de monopolio (art. 198). Cuando se trate de servicios públicos locales (y por tal deben entenderse los que se prestan para satisfacer los intereses y necesidades de la comunidad vecinal en los asuntos de su competencia, pudiendo tener por objeto el suministro de bienes y el desarrollo de actividades destinadas a la consecución de fines sociales y a promover el desarrollo económico y ciudadano de la comunidad local, art. 205), si no están reservados legalmente al municipio se prestarán en régimen de libre concurrencia, y si están reservados legalmente se podrán prestar en régimen de libre concurrencia o en régimen de monopolio (arts. 216.1 y 225.1). La imprecisión aquí estriba en identificar la posibilidad de gestión indirecta del régimen de monopolio con el régimen de libre concurrencia. La determinación de que un servicio está reservado legalmente (entre los que se incluyen el abastecimiento y depuración de aguas, art. 224.2) implica la titularidad y la competencia municipal de dicho servicio. El establecimiento de la prestación de un servicio en régimen de monopolio (con independencia de la forma de gestión directa o indirecta adoptada) requiere la tramitación de un procedimiento donde se someta a información pública la memoria justificativa (art. 226) y posteriormente se someta a la aprobación del Gobierno autonómico (art. 227). Ante la eventualidad de que pueda decidirse por el municipio la transformación del régimen de prestación del servicio reservado, el decreto regula un procedimiento concreto (art. 230). Si quiere alterarse el régimen de prestación de un servicio reservado, pasando de la libre concurrencia al monopolio, o a la inversa, se exige tramitar un procedimiento donde se acredite la conveniencia y oportunidad de dicha opción, sometiendo a información pública la correspondiente memoria. Y ello por la evidente incidencia que sobre los vecinos tendrá un régimen u otro, debiendo acreditarse en tal procedimiento si concurren o no circunstancias de interés público excluyentes de la iniciativa privada, tales como la imposibilidad física o económica de establecer más de una infraestructura de red para el servicio o la existencia de razones de seguridad, salubridad u orden público (art. 224.1). Otro ejemplo se contiene en el Decreto 179/1995, de 13 de junio, por el que se aprueba el Reglamento de Obras, Actividades y Servicios de la Entidades Locales de la Generalitat de Cataluña. Allí se establece una regulación similar. Los servicios públicos reservados podrán prestarse tanto en régimen de libre concurrencia como en 
régimen de monopolio (arts. 162 y 182). Aquí hay una evidente imprecisión y contradicción con el artículo 86.3 de la Ley de Bases, dado que la reserva excluye la libre iniciativa en los términos anteriormente expuestos. Cuando el Ayuntamiento decide prestar un servicio reservado en régimen de monopolio debe tramitar dos procedimientos (art. 162.3): un expediente para determinar el monopolio y un procedimiento para establecer el servicio. Este último requiere su sometimiento previo a información pública (art. 160). El expediente para fijar el régimen de monopolio requiere igualmente el sometimiento a información pública y su aprobación por la Comunidad Autónoma (art. 183). El servicio público reservado en régimen de monopolio puede prestarse por cualquiera de las formas de gestión (art. 182.3). Ante la eventualidad de que pueda decidirse por el municipio la transformación del régimen de prestación del servicio reservado, el decreto regula un procedimiento concreto (art. 187). Pero de manera independiente se regula la figura, no del cambio de régimen de prestación, sino de la forma de gestión. Esto es, expresamente se regula la posibilidad de que la modificación no se refiera al régimen de libre concurrencia o de monopolio, sino simplemente a la forma de gestión concreta adoptada (art. 182.3), como un procedimiento diferenciado.

18. Ni el artículo 86 de la Ley de Bases, ni el artículo 97 del Texto Refundido, ni el articulado del Reglamento de Servicios de las Corporaciones Locales de 1955 contienen previsión alguna respecto al procedimiento que debe seguirse cuando en un servicio prestado en régimen de monopolio se pretende modificar únicamente la forma de gestión del mismo, entre las permitidas legalmente. De este material normativo importa retener aquí la evidente dualidad entre modificación del régimen de prestación del servicio y modificación del régimen de gestión del servicio. La alteración del régimen de prestación del servicio (monopolio frente a libre concurrencia o viceversa) exige tanto la tramitación del correspondiente expediente de "municipalización o desmunicipalización", si se permite esta expresión gráfica, como la tramitación, dentro del mismo expediente, de la modificación de la forma de gestión del servicio (adoptando la que corresponda de entre las legalmente reguladas ${ }^{16}$. Por el contrario, si se mantiene la forma de prestación del servicio, en este caso el monopolio, simplemente se debe tramitar un procedimiento para modificar la forma de gestión del servicio, pero sin afectar al régimen de prestación anteriormente decidido.

Una interpretación analógica debe conducir a exigir la tramitación del procedimiento establecido en el artículo 97 del Texto Refundido y los artículos 56 y siguientes del Reglamento de Servicios de las Corporaciones Locales, con

16 En este sentido, debe considerarse vigente el artículo 96 del Reglamento de Servicios de las Corporaciones Locales que previene que "La Corporación podrá acordar la sustitución del régimen de monopolio por el de libre concurrencia y, a la inversa, con los mismos requisitos del acuerdo inicial de municipalización". 
la salvedad de la exigencia de la aprobación del órgano autonómico, dado el acotamiento de su competencia como medida de salvaguardia del principio de autonomía local. En consecuencia, debe exigirse la aprobación inicial por el Alcalde, elaboración de una Memoria por la Comisión de Estudio donde se fije el motivo de la modificación de la forma de gestión, su sometimiento a información pública, y la posterior aprobación por el pleno del Ayuntamiento (Sosa Wagner, 1997, p. 57; Ballesteros Fernández, 2005, p. 141). Desde una perspectiva teleológica, los intereses en juego en la determinación de la forma de gestión del servicio público de abastecimiento de agua también demandan el sometimiento a información pública de la decisión municipal. Aquí lo que entra en juego no es el interés público en la prestación obligatoria de un servicio reservado ni la libre iniciativa económica. Por el contrario, lo que está en juego es la capacidad de autoorganización de la Administración local en la prestación de un servicio de su competencia. La diferencia aquí es evidente, no se trata de constituir y organizar el servicio público prestado en régimen de monopolio, sino de modificar su forma de gestión, en los términos del artículo 30 del Reglamento de Servicios de las Corporaciones Locales. Pero tal decisión no es relevante solo ad intra de la organización. Los ciudadanos como destinatarios últimos de la prestación del servicio necesariamente deben poder manifestar sus opiniones sobre la nueva forma de gestión acordada ${ }^{17}$.

19. El trámite de información pública tiene por objeto, en este caso, más que la decisión de la prestación indirecta del servicio en sí misma, su articulación y características, proyectándose sobre un documento complejo que en gran medida resulta inaccesible para los ciudadanos. Por ello, este trámite presenta una virtualidad limitada como elemento de control de la decisión política.

En algunas Comunidades Autónomas tal control político previo puede instrumentarse a través de la figura de la consulta popular. Cuando la consulta es convocada en los términos legalmente fijados, normativamente se determina que el resultado de la consulta acerca de la externalización del servicio no es formalmente vinculante para la Corporación Local, pero materialmente sí condiciona y legitima la decisión municipal ${ }^{18}$. Por el contrario, las consultas

17 Por ejemplo, Sentencia del Tribunal Supremo de 23 de febrero de 2015 (Recurso de Casación n. ${ }^{\circ}$ 595/2013); 20 de noviembre de 2012 (Recurso de Casación en interés de Ley 80/2009). Debe tenerse en cuenta que la Sentencia del Tribunal Supremo de 21 de marzo de 2007 (Recurso de Casación n. ${ }^{\circ}$ 6098/2000) considera que en tal procedimiento se encuentra derogado el artículo 121 del Reglamento de Servicios de las Corporaciones Locales.

18 Por ejemplo, en el municipio onubense de Aracena, se convocó en marzo de 2014 una consulta popular, en los términos de la Ley 2/2001, de consultas populares locales de Andalucía, sobre la externalización del servicio de abastecimiento de agua. El Ayuntamiento convocó la consulta, forzado por la presentación de firmas exigidas por la normativa autonómica. 
legales no presentan ninguna relevancia jurídica, siendo su impacto político discutible ${ }^{19}$.

20. En todo caso, las alegaciones pueden ser informadas, no por los servicios técnicos municipales, sino por la empresa consultora, en su caso vinculada mediante un contrato de servicios para la elaboración del Pliego, dada su complejidad técnica. Obviamente, la decisión sobre tales alegaciones debe ser adoptada por el órgano legitimado democráticamente, el Pleno del Ayuntamiento, previo informe jurídico del órgano competente, el Secretario del Ayuntamiento ${ }^{20}$.

\section{C) El CONTROL JURISDICCIONAL DE LA EXTERNALIZACIÓN}

21. Ciertamente la decisión de la Administración titular del servicio optando por el cambio de modo de gestión responde al criterio de oportunidad, enmarcado en el ejercicio de la potestad de autoorganización ${ }^{21}$. Aquí el control jurisdiccional es un estricto control de legalidad. Pero lo relevante es que bajo tal concepto de oportunidad no pueden enmarcararse operaciones que cubran al concesionario de su gestión inadecuada. Aquí debe primar para el contratista el principio de riesgo y ventura ${ }^{22}$. Tampoco cabe que cuando se opte por formas privadas de gestión se otorgue cualquier tipo de preferencia en la adjudicación a asociaciones de empleados públicos de la propia Administración al socaire de su mayor especialización o implicación en la prestación del servicio, ya que ello no tiene vinculación con la solvencia económica y financiera, profesional y técnica de los posibles licitadores ${ }^{23}$. En síntesis, la externalización a un tercero debe respetar el principio de igualdad de trato y

El resultado de la consulta fue favorable a la externalización, con una participación del $56,24 \%$ de los votantes.

19 Por ejemplo, la Plataforma contra la Privatización del Canal de Isabel II convocó una consulta en 2012 en toda la Comunidad de Madrid, con más de 300 urnas, logrando reunir unas 35.000 firmas en contra de tal proceso.

20 Cfr. Sentencia del Tribunal Supremo de 21 de marzo de 2007 (Recurso de Casación n. ${ }^{\circ}$ 6098/2000).

21 Cfr. Sentencias del Tribunal Superior de Justicia de Castilla-La Mancha de 9 de marzo de 2009 (Recurso de Apelación n. ${ }^{\circ}$ 58/2008) y 2 de febrero de 2009 (Recurso de Apelación n. $\left.{ }^{\circ} 195 / 2007\right)$

22 Cfr. Sentencia del Juzgado de lo Contencioso-Administrativo n. ${ }^{\circ} 3$ de Valencia de 16 de diciembre de 2013 (Recurso contencioso-administrativo n. ${ }^{\circ}$ 4/2013).

23 La vulneración del principio de igualdad en la concurrencia fijado por la legislación básica estatal ha conducido a la STC 84/2015, de 30 de abril, a declarar inconstitucional el artículo 63 de la Ley 8/2012, que modifica el artículo 88 de la Ley 12/2001, de 21 de diciembre, en cuanto su apartado 2 permite que, cuando la gestión de los centros de atención primaria se realice por cualquiera de las formas de gestión indirecta previstas en el TRLCSP, podrá ofrecerse preferentemente a las sociedades de profesionales con personalidad jurídica 
sus expresiones específicas: la prohibición de discriminar en razón de la nacionalidad, y la libertad de establecimiento y la libre prestación de servicios, respectivamente ${ }^{24}$.

22. Aquí debe reconocerse, desde la perspectiva de la regulación procesal, una amplia legitimación a todo sujeto, individual o colectivo, interesado en defender un modo de gestión público, sin que ello suponga el reconocimiento de una acción pública. Por ejemplo, una asociación de comerciantes se encuentra plenamente legitimada para impugnar la decisión de proceder a la prestación indirecta del servicio de abastecimiento de agua en su municipio porque a tenor de sus Estatutos, su objeto y fines incorporan intereses claramente relacionados con el objeto litigioso (defensa de los derechos de los vecinos y comerciantes en su calidad de usuarios o destinatarios finales de las distintas actuaciones de los poderes públicos). Pero también, y sobre todo, porque tal decisión (el cambio del sistema de gestión del suministro del agua) está claramente vinculada con aquellos fines ${ }^{25}$.

23. En estos procedimientos por los que se inicia un proceso de transformación de la gestión directa en indirecta, la tutela cautelar en el orden contencioso se decanta por no conceder la suspensión cautelar del proceso. Las posibles consecuencias indemnizatorias que debería afrontar la Administración, en el juicio de ponderación de los intereses en juego, no se muestran prevalentes frente a la presunción de legalidad de la actuación administrativa ${ }^{26}$.

\section{BIBLIOGRAFÍA}

Ballesteros Fernández, Ángel. (2005). Manual de Gestión de Servicios Públicos Locales. Madrid: El Consultor de los Ayuntamientos y Juzgados.

CARbonell Porras, EloísA. (2013). La planta local: análisis general y perspectivas de reforma. En Díez SÁnCHEZ, J. J. (coord.), La planta del Gobierno local, dentro de

propia, que estén constituidas total o mayoritariamente por los profesionales sanitarios que presten sus servicios en el Servicio Madrileño de Salud.

24 Tal y como ha recordado por último la STC 84/2015, de 30 de abril; asumiendo la doctrina del Tribunal de Justicia de la Unión Europea establecida en la Sentencia 14 de noviembre de 2013, Caso Belgacom NV contra Interkommunale voor Teledistributie van bet Gewest Antwerpen (Integan) y otros.

25 Cfr. Sentencia del Tribunal Supremo de 23 de febrero de 2015 (Recurso de Casación n. ${ }^{\circ}$ 595/2013)

26 Cfr. Sentencia del Tribunal Superior de Justicia de Castilla-La Mancha de 8 de octubre de 2014 (Recurso de Apelación n. ${ }^{\circ}$ 67/2014), que desestima la solicitud de suspensión cautelar de la transformación en sociedad mixta de la empresa Aguas de Alcázar FM, S.A., deducida por una asociación de vecinos. 
las ponencias del VIII Congreso Asociación Española de Profesores de Derecho Administrativo. Madrid: Fundación Democracia y Gobierno Local.

Cassese, Sabino. (2006). La globalización jurídica. Madrid: Marcial Pons.

Cosculluela Montaner, Luis y Luis Medina Alcoz, L. (dirs.). 2012. Crisis económica y reforma del régimen local. Madrid: Thomson Reuters.

Díaz Lema, José Manuel. (1994). Los monopolios locales. Madrid: Montecorvo.

Domínguez Martín, Mónica y Blanca Rodríguez-Chaves Mimbrero. (2013). El régimen de constitución, organización y contratación de las Sociedades Mercantiles Locales: Estudio desde la normativa y la jurisprudencia de la Unión Europea, Madrid: La Ley.

Embid Irujo, Antonio. (2012). Crisis económica y reforma local. Anuario Aragonés del Gobierno Local, 3, pp. 443-469.

FonT I Llovert, TOMÁS y Alfredo GalÁn Galán. (2012). Gobierno local y reorganización territorial: ¡la reforma vendrá de Europa? Anuario del Gobierno Local 2011.

Galán Galán, Alfredo. (2015). La aplicación autonómica de la Ley de Racionalización y Sostenibilidad de la Administración Local. REALA: http://revistasonline. inap.es/index.php?journal $=$ REALA\&page $=$ article $\&$ op $=$ view $\&$ path $\% 5 B \% 5 D=1022$ 5 \&path $\% 5 \mathrm{~B} \% 5 \mathrm{D}=10713$

Gallego Anabitarte, Alfredo. (2003). Actividades y servicios municipales. Competencia municipal general o según Ley. Una controversia. En JuLIA OrTEGA Bernardo. Estado, Comunidades Autónomas y corporaciones locales ante la gestión de los residuos urbanos. Madrid: Marcial Pons.

MOLINA JiMÉNEZ, ANDRÉS. (2001). El servicio público de abastecimiento de agua en poblaciones. El contexto liberalizador. Valencia: Tirant lo Blanch.

Montoya MARTín, EnCARnACiÓn. (2011). Nuevas perspectivas sobre la gestión de los servicios locales: incidencia de la crisis económica y necesidad de racionalización el sector público instrumental. Anuario de Derecho Municipal, 5, pp. 167-196.

MONTOYA MARTín, ENCARNACión. (2012). Reflexiones sobre el sector público instrumental en un contexto de crisis económica: la inaplazable hora de la racionalización. En Estructuras administrativas y racionalización el gasto. VII Congreso AEPDA.

MONTOYA MARTín, ENCARNACIÓN. (2014). Medidas de redimensionamiento del sector público instrumental local antes y después de la Ley 27/2013, de 27 de diciembre de racionalización y sostenibilidad de la Administración Local. En: http://laadministracionaldia.inap.es/noticia.asp?id=1503345 
Navarro Rodríguez, Pilar y Manuel Zafra Víctor. (2014). El pretendido blindaje autonómico de competencias municipales tras la reforma de la Administración Local. Revista de Estudios de la Administración Local y Autonómica, 2, pp. 1-14.

Ortega Jiménez, María del Pilar. (2012). La racionalización del sector público instrumental local. Revista de Estudios Locales, 152, pp. 115-133.

SANTIAGO Iglesias, Diana. (2013). La transformación del sector empresarial local: prospectiva de las sociedades municipales en el actual contexto de crisis económica. Anuario de Derecho Municipal 2012, 6, pp. 101-138.

Sosa Wagner, Francisco. (1997). La gestión de los servicios públicos locales. Madrid: Civitas.

Velasco Caballero, Francisco. (2014a). El nuevo régimen local general y su aplicación diferenciada en las distintas Comunidades Autónomas. Revista Catalana de Derecho Público, 48.

Velasco Caballero, Francisco. (2014b). Reforma de la Administración Local: Una nueva distribución territorial del poder. En Federico A. Castillo Blanco, La reforma del Sector Público. Sevilla: Instituto García Oviedo, Universidad de Sevilla.

Velasco Caballero, Francisco. (2014c). Títulos competenciales y garantía constitucional de autonomía local en la Ley de Racionalización y Sostenibilidad de la Administración Local. En JuAn Alfonso SANTAMARía PASTOR (coord.), La reforma del 2013 del régimen local español. Madrid: Fundación Democracia y Gobierno Local.

Velasco Caballero, Francisco. (2015). Desarrollos normativos autonómicos de la Ley de Racionalización y Sostenibilidad de la Administración Local. Anuario de Derecho Municipal n. ${ }^{\circ}$ 8, Madrid. 